\title{
Forma Física da Ração e Pesos de Abate nas Características de Carcaça de Cordeiros em Creep Feeding
}

\author{
Marcela Abbado Neres ${ }^{1,2}$, Alda Lúcia Gomes Monteiro ${ }^{3}$, Cledson Augusto Garcia ${ }^{3}$, \\ Ciniro Costa ${ }^{4}$, Mário de Beni Arrigoni ${ }^{4}$, Guilherme Jordão Magalhães Rosa ${ }^{5}$
}

\begin{abstract}
RESUMO - Avaliaram-se 20 cordeiros machos 3/4 mestiços Suffolk submetidos a dietas isoprotéicas (21\% proteína bruta) e isoenergéticas (2,9 Mcal EM/kg MS), nas formas farelada e peletizada, e abatidos com 26 e $28 \mathrm{~kg}$ de peso vivo. Os cordeiros tiveram acesso ao creep feeding, permanecendo com as ovelhas até atingirem o peso de abate. A ração peletizada promoveu maior rendimento de carcaça quente $(54,18 \%$ para ração peletizada e 52,04\% para ração farelada) e maior rendimento verdadeiro (58,37\% peletizada e $56,66 \%$ farelada). O peso vivo final não interferiu nos pesos das carcaças quente e fria $(12,79$ e $13,05 \mathrm{~kg}$ para 26 e $28 \mathrm{~kg}$ de peso vivo final, respectivamente). Não houve interferência da forma física da ração e do peso vivo final dos animais na área do olho de lombo e no comprimento do lombo. A largura do lombo e a máxima espessura de gordura foram maiores nas carcaças dos animais que receberam ração peletizada e a mínima espessura foi inferior nos animais abatidos com $26 \mathrm{~kg}$ de peso vivo $(1,48 \mathrm{e} 1,77 \mathrm{~cm}$ para os cordeiros abatidos com 26 e $28 \mathrm{~kg}$, respectivamente). Concluiu-se que o uso da ração peletizada proporcionou aos cordeiros melhoria dos índices de rendimento de carcaça quente, rendimento biológico, profundidade do lombo e índice de compacidade da carcaça. O peso vivo de $26 \mathrm{~kg}$ apresentou-se como o mais satisfatório para o abate de cordeiros, por apresentar características de carcaça semelhantes àqueles abatidos com $28 \mathrm{~kg}$.
\end{abstract}

Palavras-chave: carcaça, cordeiros, creepfeeding, suplementação

\section{Diet Physical Form and Slaughter Weight on Carcass Traits of Lambs on Creep Feeding}

\begin{abstract}
Twenty 3/4 Suffolk male lambs were fed ground and pelleted diets and slaughtered at 26 and $28 \mathrm{~kg}$ of liveweight. Diets were isoprotein $(21 \% \mathrm{CP})$ and isoenergetic $(2.9 \mathrm{Mcal} \mathrm{ME} / \mathrm{kg} \mathrm{DM})$. Lambs had free entrance on creep feeding, staying with their mothers until reaching slaughter weight. Pelleted diet resulted in higher hot dressing-out percentages (54.18\% for pelleted diet and $52.04 \%$ for ground one) and higher true dressing-out percentages ( $58.37 \%$ for pelleted diet and $56.66 \%$ for ground one). Hot and cold dressingout percentages were not affected by final liveweight (12.79 and $13.05 \mathrm{~kg}$ for 26 and $28 \mathrm{~kg}$ slaughter live weight, respectively). Diet physical form and final live weight did not affect Longissimus muscle area and length. Loin width and maximal fat depth were higher for lambs fed pelleted diet and minimum fat depth was lower for lambs slaughtered at $26 \mathrm{~kg}$ of live weight $(1.48 \mathrm{and} 1.77 \mathrm{~cm}$ for lambs slaughtered at 26 and $28 \mathrm{~kg}$, respectively). It was concluded that pelleted diets provided better hot carcass and biological dressing-out percentages and loin depth and compactness carcass index. Live weight of $26 \mathrm{~kg}$ was considered the most useful for lambs slaughter because presented similar carcass traits compared to $28 \mathrm{~kg}$.
\end{abstract}

Key Words: carcass, lambs, creep feeding, supplemmentation

\section{Introdução}

O consumo de carne magra tem-se intensificado em muitos países devido a mudanças no padrão de consumo. O excesso de gordura, como conseqüência do abate tardio, além de afetar a qualidade da carcaça, repercute na viabilidade econômica do sistema de produção, tendo em vista a transformação de parte dos nutrientes ingeridos em tecido indesejável. Atualmente, o consumidor tem procurado carne ovina mais tenra, com menor teor de gordura, estimulando a produção de animais mais precoces.

No Brasil, entretanto, a comercialização da carne ovina ainda é feita em função do peso vivo, não sendo levados em consideração o peso da carcaça, a conformação e a relação entre as proporções de múscu-

\footnotetext{
1 Parte da tese de Doutorado do primeiro autor.

2 Professora do C.C.A., UNIOESTE, Mal. Cândido Rondon, PR. Rua Pernambuco, 1777. Cx. P. 91, CEP: 85960-000. E.mail: neresmg@fsnet.com.br

3 Professor da Faculdade de Ciências Agrárias da Universidade de Marília, Marília, SP. E.mail: adalgm@terra.com.br; cagarcia@unimar.br

4 Professor do Departamento de Nutrição e Melhoramento Animal/UNESP, Botucatu, SP. E.mail: secdmna@fca.unesp.br; arrigoni@fca.unesp.br

5 Professor do Departamento de Bioestatística/UNESP, Botucatu, SP. E.mail: kiba@ibb.unesp.br
} 
los, ossos e gordura (SOUSA, 1993; OSÓRIOetal., 1996).

Nas pastagens nativas, dificilmente se conseguem boa produtividade e qualidade de carne ovina, devido principalmente à deficiência de nutrientes, havendo necessidade da utilização de pastagens cultivadas, suplementação em pastejo e/ou confinamento para explorar o máximo potencial genético dos animais.

MACEDO (1998), ao comparar dois sistemas de criação (confinamento e pastagem), observou que cordeiros Bergamácia x Corriedale e Hampshire Down x Corriedale terminados em confinamento foram os que apresentaram maior ganho de peso. Considerando as variáveis de importância qualitativa e econômica relacionadas a pesos e rendimentos de carcaça, perdas no resfriamento, índices de compacidade e peso dos cortes, o sistema de terminação em confinamento mostrou-se superior à pastagem. Das variáveis relacionadas com níveis de gordura (cobertura, cor e espessura) e ossos, todas apresentaram valores superiores para o grupo de cordeiros confinados. Porém, os teores de tecido adiposo das carcaças dos dois sistemas de terminação estiveram dentro da faixa que permite denominá-las de alta qualidade e que a criação de cordeiros para a produção de carne, em confinamento, foi economicamente viável ( $\mathrm{R} \$ 275,13$ a mais), tendo apresentado retorno econômico superior ao sistema à pasto. Num módulo de 100 animais, o lucro total a pasto foi de $\mathrm{R} \$ 1304,50$ e no confinamento, de R $\$ 1579,63$.

SUMMERS et al. (1978) avaliaram cordeiros desmamados com $18 \mathrm{~kg}$ e terminados com ração contendo $13 \%$ de PB; no segundo tratamento, os cordeiros foram desmamados com $18 \mathrm{~kg}$ e tiveram acesso à pastagem de bluegrass; no terceiro tratamento, não foram desmamados e tiveram acesso à pastagem + concentrado com $13 \% \mathrm{~PB}$; e no quarto tratamento, não foram desmamados e tiveram acesso à pastagem sem concentrado. $\mathrm{O}$ abate foi realizado aos $45 \mathrm{~kg}$ de peso vivo. Os cordeiros recém-desmamados e alimentados com forragem + concentrado produziram melhores carcaças em relação aos cordeiros desmamados e alimentados em confinamento e com características semelhantes aos não desmamados e alimentados com concentrado + forragem.

$\mathrm{Na}$ ovinocultura nacional, os cordeiros são abatidos ao redor de $30 \mathrm{~kg}$ de peso vivo. SIQUEIRA et al. (1998) avaliaram o efeito do peso vivo ao abate de 28 , 32,36 e $40 \mathrm{~kg}$ sobre a eficiência de produção de cordeiros da raça Hampshire Down terminados em confinamento. Sob o ponto de vista de qualidade de carcaça, os pesos vivos de abate de 28,32 e $36 \mathrm{~kg}$ mostraram-se adequados, ao passo que o abate com $40 \mathrm{~kg}$ redundou em carcaças com altos níveis de gordura. Em termos econômicos, porém, $28 \mathrm{~kg}$ foi o melhor peso vivo ao abate, enquanto com $40 \mathrm{~kg}$ houve perda de renda líquida.

BUENO et al. (1998) verificaram que o aumento de 16 para $46 \mathrm{~kg}$ do peso vivo ao abate de cordeiros Suffolk aumentou o peso das carcaças frias, do rendimento de carcaça e da porcentagem de gordura. O aumento do peso de abate dos cordeiros refletiu em diminuição linear da porcentagem de ossos e aumento de gordura em todos os cortes. A porcentagem de músculos manteve-se constante no traseiro e diminuiu no costilhar. Isso mostra que o aumento da maturidade dos animais, determinado pelo aumento de peso, levou à maior deposição de gordura nas carcaças e à diminuição da porcentagem de ossos, sem alterar a de músculos, conforme foi citado por OWENS et al. (1993). A área do olho de lombo aumentou linearmente com o peso de abate. A espessura da gordura subcutânea sofreu efeito linear positivo com o peso de abate e correlação com a porcentagem de gordura na carcaça, mostrando sua utilidade para avaliar carcaças de cordeiros.

SILVA et al. (1999a) não encontraram diferenças significativas para proporção de ossos, músculos e gordura, ao compararem dois pesos de abate $(28 \mathrm{e}$ $33 \mathrm{~kg}$ ) em cordeiros oriundos do acasalamento de carneiro Texel com ovelhas mestiças Texel x Ideal. Entretanto, SILVA et al. (1999b) verificaram que os cordeiros com menor peso de corpo vazio apresentaram maior proporção de coração, rins, pulmão+traquéia, patas e sangue, em relação aos animais de maior peso de corpo vazio. Entre os constituintes corporais estudados, o trato gastrintestinal apresentou crescimento tardio, enquanto os outros componentes mostraram crescimento precoce.

SOUSA (1993), ao estudar duas idades de abate (90 e 180 dias) em cordeiros Romney Marsh criados em regime de pastagem de azevém, campo nativo e milheto, concluiu que o abate aos 90 dias apresentou vantagem sobre o realizado aos 180 dias de idade, em função do maior rendimento de carcaça e da menor proporção de gordura/músculo na paleta.

Diante do exposto, o objetivo do trabalho foi estudar as características de carcaça de cordeiros mestiços $3 / 4$ Suffolk submetidos a duas formas físicas de ração e dois pesos de abate. 


\section{Material e Métodos}

Foram utilizadas 20 fêmeas com suas crias, 3/4 mestiços Suffolk, com parto simples, divididas em delineamento experimental inteiramente casualizado em esquema fatorial (2x2), sendo duas rações (farelada e peletizada) e dois pesos de abate (26 e $28 \mathrm{~kg}$ de peso vivo).

Foram utilizados cinco cordeiros machos inteiros por tratamento. Após o nascimento, os cordeiros foram pesados e colocados junto com as ovelhas em piquetes de gramínea estrela branca (Cynodon plectostachyus). Para cada tratamento foram utilizados dois piquetes de $2750 \mathrm{~m}^{2}$.

A ração dos cordeiros foi constituída de $62 \%$ de milho, $22 \%$ de farelo de soja, $15 \%$ de feno de alfafa e $1 \%$ de sal mineral, com $17,99 \%$ de PB e $2,96 \mathrm{Mcal}$ de EM/kg (NATIONAL RESEARCH COUNCIL NRC, 1985).

As ovelhas receberam ração para lactação duas vezes ao dia (600 g no total) e feno de Tifton 85 à vontade. As dietas dos cordeiros foram fornecidas em creep feeding, em duas refeições diárias (8 e 16 h).

Após atingirem o peso vivo final, os cordeiros permaneceram em jejum com água por 12 horas e foram pesados novamente. Após o abate, o conteúdo do trato gastrintestinal foi retirado para determinação do peso do corpo vazio, visando determinar o rendimento biológico (DELFA et al., 1991). Após a evisceração, obteve-se o peso da carcaça quente.

$\mathrm{Na}$ câmara fria, as carcaças foram resfriadas por 24 horas a $5^{\circ} \mathrm{C}$ e penduradas pela articulação tarso metatarsiana, em ganchos próprios com distanciamento de $17 \mathrm{~cm}$. Posteriormente, as carcaças foram pesadas, obtendo-se o peso da carcaça fria, calculando-se a porcentagem de perda de peso por resfriamento e os rendimentos comercial e biológico. Em seguida, foram divididas longitudinalmente, sendoo lado esquerdo seccionado em sete regiões anatômicas: paleta, perna, pescoço, costela, costela descoberta, lombo e baixo, conforme COLOMER-ROCHER (1988), OSÓRIO (1992), FERNANDES (1994) e GARCIA (1998).

No lombo, foi desenhado o perímetro do músculo Longissimus dorsi, para o cálculo da área do olho de lombo entre a $12^{\mathrm{a}}$ e $13^{\mathrm{a}}$ costelas e realizadas as mensurações transversais de largura máxima, profundidade máxima, espessura mínima de gordura sobre o músculo e espessura máxima de gordura de cobertura no perfil do lombo. Para o cálculo do índice de compacidade da carcaça, dividiu-se o peso da carcaça fria pelo comprimento interno da carcaça.
A análise estatística para cada uma das variáveis de carcaça foi realizada utilizando-se a técnica da análise de variância para experimento inteiramente casualizado, com tratamentos dispostos num esquema fatorial $2 \times 2$, com dois tipos de ração e dois pesos de abate (COCHRAM e COX, 1976).

Os cálculos foram efetuados utilizando-se o procedimento GLM do programa computacional SAS (SAS, 1985). Na discussão dos resultados, sempre que a interação entre os tratamentos foi significativa, uma única tabela com as médias de cada tratamento foi apresentada, incluindo as comparações pertinentes.

\section{Resultados e Discussão}

As médias e coeficientes de variação para peso vivo de abate (PVA), peso do corpo vazio (PCV), peso da carcaça quente (PCQ), peso da carcaça fria (PCF), rendimento comercial (RC), rendimento biológico $(\mathrm{RB})$ e quebra no resfriamento $(\mathrm{QR})$ encontram-se na Tabela 1.

As médias dos pesos vivos finais no experimento foram 26,31 e $27,91 \mathrm{~kg}$ para os valores estabelecidos de 26 e $28 \mathrm{~kg}$, respectivamente. Os cordeiros que receberam ração farelada e peletizada apresentaram perda de peso vivo após o jejum de 7,91 e 7,60\%, respectivamente. As perdas quanto ao peso de abate (26 e $28 \mathrm{~kg}$ ) foram de 7,43 e 8,07\%, respectivamente. Segundo OSÓRIO (1992), a perda de peso vivo após o jejum pode variar de 6,0 a 8,0\%, quando o jejum é de 17 a 18 horas, entretanto, quando os animais dispõem de água, as perdas são menores.

É interessante observar a relação entre aumento de peso vivo do animal e aumento de peso da carcaça. Os animais apresentaram diferença de $1,6 \mathrm{~kg}$ para abate aos 26 e $28 \mathrm{~kg}$, mas apresentaram PCQ semelhantes $(13,17$ e 13,45 kg). Portanto, a eficiência na transformação do alimento consumido para peso vivo e peso de carcaça não foi a mesma, refletindo a variação do rendimento da carcaça em relação ao peso vivo, conforme comentado por SOUSA (1993).

As duas formas físicas da ração e os dois pesos de abate mostraram-se semelhantes $(p>0,05)$ quanto aos pesos de carcaça quente e fria. Conforme apresenta-se na Tabela 1, para o abate aos $26 \mathrm{~kg}$, encontraram-se valores de $13,17 \mathrm{~kg}$ de PCQ e $12,79 \mathrm{~kg}$ de $\mathrm{PCF}$, enquanto para o abate aos $28 \mathrm{~kg}$ os resultados foram de 13,45 e 13,05 kg para PCQ e PCF, respectivamente. MACEDO (1998), com pesos de abate de 30 a $32 \mathrm{~kg}$, obteve valores médios de 13,37 kg para PCQ e 12,92 kg PCF em cordeiros da raça Hampshire 
NERES et al.

Tabela 1 - Médias obtidas para peso vivo ao abate (PVA), peso do corpo vazio (PCV), peso da carcaça quente (PCQ), peso da carcaça fria (PCF), rendimento da carcaça quente (RCQ), rendimento comercial $(R C)$, rendimento biológico (RB) e quebra no resfriamento (QR), em cordeiros $3 / 4$ Suffolk, de acordo com a forma física da ração e o peso de abate

Table 1 - Means for slaughter live weight (SLW), empty live weight (ELW), hot carcass weight (HCW), cold carcass weight (CCW), hot dressing-out (HDO), commercial dressing-out (CDO), biological dressing-out (BDO) and cooling loss (CL) of 3/4 Suffolk lambs, according to diet physical form and slaughter weight

\begin{tabular}{|c|c|c|c|c|c|c|c|}
\hline \multirow[t]{2}{*}{$\begin{array}{l}\text { Parâmetro } \\
\text { Parameter }\end{array}$} & \multicolumn{2}{|c|}{$\begin{array}{c}\text { Ração } \\
\text { Diet } \\
\end{array}$} & \multirow[t]{2}{*}{$\mathrm{p}$-value } & \multicolumn{2}{|c|}{$\begin{array}{l}\text { Peso vivo final }(\mathrm{kg}) \\
\text { Final live weight }\end{array}$} & \multirow[t]{2}{*}{ p-value } & \multirow[t]{2}{*}{$\mathrm{CV}(\%)$} \\
\hline & $\begin{array}{l}\text { Farelada } \\
\text { Ground }\end{array}$ & $\begin{array}{l}\text { Peletizada } \\
\text { Pelleted } \\
\end{array}$ & & 26 & 28 & & \\
\hline $\begin{array}{l}\text { PVA }(\mathrm{kg}) \\
S L W(k g)\end{array}$ & $25,25^{\mathrm{a}}$ & $24,91^{\mathrm{a}}$ & 0,3851 & $24,54^{b}$ & $25,62^{\mathrm{a}}$ & 0,0118 & 3,25 \\
\hline $\begin{array}{l}\mathrm{PCV}(\mathrm{kg}) \\
E L W(k g)\end{array}$ & $23,19^{\mathrm{a}}$ & $23,12^{\mathrm{a}}$ & 0,8823 & $22,75^{\mathrm{a}}$ & $23,56^{\mathrm{a}}$ & 0,1111 & 4,43 \\
\hline $\begin{array}{l}\mathrm{PCQ}(\mathrm{kg}) \\
H C W(\mathrm{~kg})\end{array}$ & $13,14^{\mathrm{a}}$ & $13,48^{\mathrm{a}}$ & 0,2209 & $13,17^{\mathrm{a}}$ & $13,45^{\mathrm{a}}$ & 0,3286 & 4,42 \\
\hline $\begin{array}{l}\mathrm{PCF}(\mathrm{kg}) \\
C C W(\mathrm{~kg})\end{array}$ & $12,79^{\mathrm{a}}$ & $13,05^{\mathrm{a}}$ & 0,3835 & $12,79^{\mathrm{a}}$ & $13,05^{\mathrm{a}}$ & 0,3879 & 4,98 \\
\hline $\begin{array}{l}\mathrm{RCQ}(\%) \\
H D O(\%)\end{array}$ & $52,04^{b}$ & $54,18^{a}$ & 0,0178 & $53,74^{\mathrm{a}}$ & $52,48^{\mathrm{a}}$ & 0,139 & 3,28 \\
\hline $\begin{array}{l}\mathrm{RC}(\%) \\
C D O(\%)\end{array}$ & $50,65^{\mathrm{a}}$ & $52,45^{\mathrm{a}}$ & 0,0543 & $52,16^{\mathrm{a}}$ & $50,94^{\mathrm{a}}$ & 0,1775 & 3,28 \\
\hline $\begin{array}{l}\mathrm{RB}(\%) \\
B D O(\%)\end{array}$ & $56,66^{\mathrm{b}}$ & $58,37^{\mathrm{a}}$ & 0,0262 & $57,96^{\mathrm{a}}$ & $57,07^{\mathrm{a}}$ & 0,2183 & 8,83 \\
\hline $\begin{array}{l}\mathrm{QR}(\%) \\
C L(\%) \\
\end{array}$ & $2,70^{\mathrm{a}}$ & $3,19^{\mathrm{a}}$ & 0,4093 & $2,92^{\mathrm{a}}$ & $2,96^{\mathrm{a}}$ & 0,9375 & 42,38 \\
\hline
\end{tabular}

Médias seguidas de letras na linha diferem $(p<0,05)$ pelo teste de Tukey. Means, within a row, followed by different letters are different $(p<.05)$ by Tukey test.

Down e SILVA et al (1998), abatendo animais mestiços (Texel x Ideal) aos $28 \mathrm{~kg}$, encontraram $13,0 \mathrm{~kg}$ para PCQ e 12,79 kg para PCF. Verifica-se assim proximidade desses resultados com os obtidos neste ensaio. Entretanto, SIQUEIRA (1998), trabalhando com animais Hampshire Down abatidos aos $28 \mathrm{~kg}$ de peso vivo, encontrou $12,3 \mathrm{~kg}$ para PCQ e $11,7 \mathrm{~kg}$ para $\mathrm{PCF}$, valores inferiores aos resultados deste ensaio.

Os rendimentos de carcaça quente foram superiores nos animais que receberam ração peletizada $(p<0,05)$, não diferindo $(p>0,05)$ entre os pesos vivos finais. Para rendimento comercial não foram observadas diferenças significativas $(p>0,05)$ para forma física da ração e pesos de abate. Para o rendimento biológico, o uso da ração peletizada promoveu melhor rendimento $(\mathrm{p}<0,05)$, não sendo observada diferença $(p>0,05)$ para peso vivo final.

Segundo SAÑUDO e SIERRA (1986), os rendimentos de carcaça variam de 40 a $60 \%$, de acordo com a raça, os cruzamentos e o sistema de criação, sendo superiores em animais confinados e produtos de cruzamentos, utilizando-se raças específicas para carne. Também SANUDO et al. (1998) encontraram maior rendimento da carcaça quente em cordeiros não desmamados $(52,2 \%)$ e que permaneceram com as ovelhas até o peso de abate, quando comparados com cordeiros desmamados $(49,7 \%)$ e confinados.

Quanto ao rendimento comercial, o valor médio obtido neste ensaio foi de 51,55\%, superior aos $42,2 \%$ encontrados por SIQUEIRA et al. (1998), em animais da raça Hampshire Down abatidos aos $28 \mathrm{~kg}$, e GARCIA (1998), que obteve rendimento comercial de 43,97\%, em animais mestiços Texel abatidos com 30 a $32 \mathrm{~kg}$ de peso vivo.

Experimentalmente, o rendimento biológico é o mais preciso, pois é eliminado o conteúdo digestivo em seu cálculo (MACEDO, 1998). Os valores obtidos do rendimento biológico foram superiores aos encontrados por GARCIA et al. (1999a), que obtiveram rendimentos de 53,55 e 53,99\% para animais mestiços Texel abatidos aos 30 e $34 \mathrm{~kg}$ de peso vivo; MARTINS et al (1999), com 54,86\%, em cordeiros mestiços Texel abatidos aos 30 e $32 \mathrm{~kg}$ de peso vivo; e SIQUEIRA et al (1998), com 54,3\%, em animais da raça Hampshire Down abatidos aos $28 \mathrm{~kg}$ de peso vivo.

Não houve diferença $(p>0,05)$ entre os tratamentos para quebra no resfriamento, com valor médio de $2,94 \%$. Ao ser resfriada, a carcaça sofre quebra, cuja porcentagem é influenciada pela espessura da gordura de cobertura (LOSSE et al., 1981). 
952 Rev. bras. zootec.

MACEDO (1998) encontrou, em animais mestiços Bergamácia x Corriedale, valores de quebra no resfriamento de $4,11 \%$, quando terminados a pasto, e $3,35 \%$, em confinamento, enquanto FERNANDES (1994) obteve valores de 3,54\% para animais Corriedale e 2,83\% para os mestiços Ile de France x Corriedale.

As medidas objetivas do músculo L. dorsi, área de olho de lombo (AOL), largura máxima (A), profundidade máxima (B), espessura máxima de gordura de cobertura no lombo (J) e índice de compacidade da carcaça (ICC), encontram-se na Tabela 2 e as medidas de espessura mínima de gordura sobre o músculo L. dorsi (C), na Tabela 3 .

A AOL e a máxima largura não foram afetadas pelos diferentes tratamentos ( $p>0,05)$. A profundidade e a espessura máxima de gordura foram maiores $(\mathrm{p}<0,05)$ nas carcaças dos cordeiros que receberam ração peletizada. Para a espessura mínima de gordura, houve efeito $(p<0,05)$ de interação entre peso vivo final e forma física da ração. Os animais que receberam ração peletizada e foram abatidos aos $26 \mathrm{~kg}$ apresentaram maior espessura mínima de gordura superior aos demais tratamentos, mesmo apresentando menores pesos de abate.

As medidas objetivas do lombo obtidas neste ensaio foram superiores àquelas encontradas por FERNANDES (1994), que obteve em animais mestiços Ile de France $x$ Corriedale as seguintes medidas: (A) 51,0 mm; (B) 24,1 mm; (C) 1,43 mm; e (J) 3,27 mm e próximos aos obtidos por GARCIA (1999b) em cor- deiros mestiços Texel: (A) 54,3 mm; (B) 27,8 mm; (C) 1,6 mm; e (J) 3,2 mm. Os valores para AOL foram próximos aos encontrados por MACEDO (1998) em cordeiros mestiços Bergamácia $\mathrm{x}$ Corriedale, $10,21 \mathrm{~cm}^{2} \mathrm{em}$ animais confinados e superiores aos valores encontrados por KIRTON et al. (1995) em cordeiros Suffolk, que foi de $9,5 \mathrm{~cm}^{2}$.

Os animais que receberam ração peletizada apresentaram maior índice de compacidade da carcaça ( $p<0,05)$. Segundo Thwaites et al. (1964), citados por FERNANDES (1994), o índice de compacidade da carcaça é uma medida indireta da conformação e serve para indicar a distribuição de carne e de gordura na carcaça. Os valores obtidos foram superiores aos encontrados por diversos autores, com cordeiros abatidos ao redor de $30 \mathrm{~kg}$ de peso vivo: MACEDO (1998) obteve valores de 0,22 e $0,19 \mathrm{~kg} / \mathrm{cm}$ em animais terminados a pasto e confinamento, respectivamente; FERNANDES (1994), 0,25, em animais mestiços; MARTINS et al. (1999), 0,21 e 0,22 (kg/cm) em cordeiros mestiços recebendo 60 e $70 \%$ NDT, respectivamente; GARCIA (1998), 0,24 (kg/cm) em animais 1 12 Texel; e OSÓRIO et al. (1996), 0,23 kg/cm, em cordeiros Texel, indicando que os pesos de abate entre 26 e 28 kg não prejudicaram a conformação da carcaça.

A superioridade de algumas características de carcaça nos cordeiros que receberam ração peletizada mostra que a peletização acarretou aumento da proporção dos componentes de carcaça. O uso de ração

Tabela 2 - Médias obtidas para área de olho de lombo (AOL), largura máxima (A), profundidade máxima (B), espessura máxima de gordura (J) e índice de compacidade da carcaça (ICC), em cordeiros $3 / 4$ Suffolk, de acordo com a forma física da ração e o peso de abate

Table 2 - Means for Longissimus muscle area (LMA), maximum width (W), maximum depth (D), larger fat depth (J) and index of carcass compactness (ICC) of $3 / 4$ Suffolk lambs, according to diet physical form and slaughter weight

\begin{tabular}{|c|c|c|c|c|c|c|c|}
\hline \multirow[t]{2}{*}{$\begin{array}{l}\text { Parâmetro } \\
\text { Parameter }\end{array}$} & \multicolumn{2}{|c|}{$\begin{array}{c}\text { Ração } \\
\text { Diet }\end{array}$} & \multirow[t]{2}{*}{ p-value } & \multicolumn{2}{|c|}{$\begin{array}{l}\text { Peso vivo final }(\mathrm{kg}) \\
\text { Final live weight }(\mathrm{kg})\end{array}$} & \multirow[t]{2}{*}{ p-value } & \multirow[t]{2}{*}{$\mathrm{CV}(\%)$} \\
\hline & $\begin{array}{c}\text { Farelada } \\
\text { Ground }\end{array}$ & $\begin{array}{l}\text { Peletizada } \\
\text { Pelleted }\end{array}$ & & 26 & 28 & & \\
\hline $\begin{array}{l}\operatorname{AOL}\left(\mathrm{cm}^{2}\right) \\
\operatorname{LMA}\left(\mathrm{cm}^{2}\right)\end{array}$ & $10,80^{\mathrm{a}}$ & $10,88^{\mathrm{a}}$ & 0,8290 & $10,49^{\mathrm{a}}$ & $11,19^{\mathrm{a}}$ & 0,0875 & 7,65 \\
\hline $\begin{array}{l}\mathrm{A}(\mathrm{mm}) \\
W(\mathrm{~mm})\end{array}$ & $54,21^{\mathrm{a}}$ & $54,58^{\mathrm{a}}$ & 0,7599 & $53,21^{\mathrm{a}}$ & $55,58^{\mathrm{a}}$ & 0,0674 & 4,81 \\
\hline $\begin{array}{l}\mathrm{B}(\mathrm{mm}) \\
D(\mathrm{~mm})\end{array}$ & $26,98 \mathrm{a}$ & $29,70^{\mathrm{b}}$ & 0,0290 & $27,66^{\mathrm{a}}$ & $29,02^{\mathrm{a}}$ & 0,2487 & 8,64 \\
\hline $\begin{array}{l}\mathrm{J}(\mathrm{mm}) \\
J(\mathrm{~mm})\end{array}$ & $3,39^{a}$ & $4,75^{\mathrm{b}}$ & 0,0273 & $4,12^{\mathrm{a}}$ & $4,02^{\mathrm{a}}$ & 0,8506 & 29,34 \\
\hline $\begin{array}{l}\mathrm{ICC} \\
\mathrm{ICC}\end{array}$ & $0,26^{\mathrm{a}}$ & $0,28^{\mathrm{b}}$ & 0,0311 & $0,26^{\mathrm{a}}$ & $0,27^{\mathrm{a}}$ & 0,6321 & 6,25 \\
\hline
\end{tabular}

Médias seguidas de letras na linha diferem $(p<0,05)$ pelo teste de Tukey.

Means, within a row, followed by different letters are different $(p<.05)$ by Tukey test. 
Tabela 3 - Espessura mínima de gordura sobre o músculo L. dorsi (C), em mm, em relação à forma física da ração e ao peso vivo de abate, em cordeiros Suffolk alimentados em creep feeding

Table 3 - Minimal loin fat depth (cm) of Suffolk lambs fed on creep feeding, according to physical form and slaughter live weight

\begin{tabular}{|c|c|c|c|}
\hline \multirow[t]{2}{*}{$\begin{array}{l}\text { Forma física da ração } \\
\text { Ration physical form }\end{array}$} & \multicolumn{2}{|c|}{$\begin{array}{l}\text { Peso vivo final }(\mathrm{kg}) \\
\text { Slaughter live weight }\end{array}$} & \multirow[t]{2}{*}{$\begin{array}{l}\mathrm{p} \text {-value } \\
p \text {-value }\end{array}$} \\
\hline & 26 & 28 & \\
\hline $\begin{array}{l}\text { Farelada } \\
\text { Ground }\end{array}$ & $1,48^{\mathrm{aA}}$ & $1,77^{\mathrm{aA}}$ & 0,1192 \\
\hline Peletizada & $2,30^{\mathrm{bB}}$ & $1,64^{\mathrm{aA}}$ & 0,0014 \\
\hline $\begin{array}{l}\text { Pelleted } \\
\text { p-value } \\
\mathrm{CV}=14,78 \%\end{array}$ & 0,0002 & 0,4613 & \\
\hline
\end{tabular}

farelada provavelmente se refletiu em aumento dos componentes de não carcaça. Estas diferenças podem estar relacionados com os diferentes sítios de digestão das duas formas físicas da ração, ou seja, a ração farelada provavelmente sofreu maior digestão intestinal e a peletizada, maior digestão ruminal.

\section{Conclusões}

O uso da ração peletizada proporcionou aos cordeiros melhoria dos índices de rendimento de carcaça quente, rendimento verdadeiro, profundidade do lombo e índice de compacidade da carcaça.

O peso vivo de $26 \mathrm{~kg}$ apresentou-se satisfatório para o abate dos cordeiros mestiços Suffolk, considerando que as características de carcaça foram semelhantes àqueles abatidos com $28 \mathrm{~kg}$.

\section{Referências Bibliográficas}

BUENO, M.S., CUNHA, E.A., SANTOS, L.E. et al. Avaliação de carcaças de cordeiros Suffolk abatidos com diferentes pesos vivos. In: REUNIÃO ANUAL DA SOCIEDADE BRASILEIRA DE ZOOTECNIA, 35, 1998, Botucatu, SP. Anais... Botucatu: SBZ, 1998. p.573-78.

COCHRAM, W.G., COX, G.M. 1976. Experimental designs. 2.ed. New York: Wiley. 611p.

COLOMER-ROCHER, F. Estudios de los parametros que definem los caracteres cuantitativos y cualitativos de las canales. In: CURSO INTERNACIONAL SOBRE PRODUCCIÓN DE CARNE Y LECHE COM BASES EN PASTOS Y FORRAGES, La Coruna, Espana, 1988. Proceedings... La Coruna, 1988. 108p.

DELFA, R., GONCALÉZ, C., TEIXEIRA, A. 1991. El quinto quarto. Ovis, 17:48-68.
FERNANDES, S. Peso vivo ao abate e características de carcaça de cordeiros da raça Corriedale e mestiços Ile de France $x$ Corriedale recriados em confinamento. Botucatu, SP: FMVZ UNESP, 1994, 82p. Dissertação (Mestrado em Zootecnia) Universidade Estadual Paulista, 1994.

GARCIA, C.A. Avaliação de resíduo de panificação "biscoito" na alimentação de ovinos e nas características quantitativas e qualitativas da carcaça. Jaboticabal, SP: FCAV-UNESP, 1998. 79p. Dissertação (Mestrado em Zootecnia) - Universidade Estadual Paulista, 1998.

GARCIA, C.A., SILVA SOBRINHO, A.G., GASTALDI, K.A. Influência das diferentes relações volumoso:concentrado e pesos de abate de cordeiros confinados. 1. Rendimento dos cortes e características das carcaças. In: REUNIÃO ANUAL DA SOCIEDADE BRASILEIRA DE ZOOTECNIA, 36, 1999, Porto Alegre, RS. Anais... Porto Alegre: SBZ, 1999a. p.339.

GARCIA, C.A., SILVA SOBRINHO, A.G., GASTALDI, K.A. Influencia das diferentes relações volumoso:concentrado e pesos de abate de cordeiros confinados. 2. Medidas objetivas e subjetivas das carcaças. In: REUNIÃO ANUAL DA SOCIEDADE BRASILEIRA DE ZOOTECNIA, 36, 1999, Porto Alegre, RS. Anais... Porto Alegre: SBZ, 1999b. p.340.

KIRTON, A. H., CARTER, A. H., CLARKE, J.N. et al. 1995. A comparison between 15 ram breeds for export lamb production. 1. Liveweights, body components, carcass measurements, and composition. New Zealand J. Agric. Res., 38:347-60.

LOSSE, E.M., JARDIM, P.O.C., OSÓRIO, J.C.S. et al. Estudo comparativo de carcaças de cordeiros Ideal com cruzas Ideal $x$ Texel. In: REUNIÃO ANUAL DA SOCIEDADE BRASILEIRA DE ZOOTECNIA, 18, 1981, Goiânia. Anais...Goiânia: SBZ, 1981. p.396.

MACEDO, F.A.F. Desempenho e características de carcaças de cordeiros Corriedale e mestiços Bergamácia x Corriedale e Hampshire Down $x$ Corriedale, terminados em pastagem e confinamento. Botucatu, SP: FMVZ - UNESP, 1998. 72p. Tese (Doutorado em Zootecnia) - Universidade Estadual Paulista, 1998.

MARTINS, E.N., MACEDO, F.A.F., MACEDO, R.M.G. et al. Desempenho e características quantitativas da carcaça de cordeiros mestiços Texel, terminados em confinamento, com diferentes níveis de energia. In: REUNIÃO ANUAL DA SOCIEDADE BRASILEIRA DE ZOOTECNIA, 36, 1999, Porto Alegre, RS. Anais... Porto Alegre: SBZ, 1999. p.347.

NATIONAL RESEARCH COUNCIL - NRC. 1985. Nutrient requeriments of sheep. Washington: National Academy Press. 99p.

OSÓRIO, J.C.S. Estudio de la calidad de canales comercializadas en el tipo ternasco segun la procedencia: bases para la mejora de dicha calidad en Brazil. Zaragoza, 1992. 335p. Tese (Doutorado em Veterinária) - Faculdad de Veterinaria, Universidade de Zaragoza, 1992.

OSÓRIO, J.C., OLIVEIRA, A.P.N., POUEY, J.L. 1996. Produção de carne em ovinos de cinco genótipos. 3. Perdas e morfologia. Ciência Rural, 26(3): 477-81.

OWENS, F.N., DUBESKI, P., HANSON, C.F. 1993.Factors that alter the growth and development of ruminant. J. Anim. Sci., 71:3138-50.

SAÑUDO, C., SIERRA, I. 1986. Calidad de la canal en la espécie ovina. Revista Ovis, 1:127-53.

SAÑUDO, C., SIERRA, J.L., OLLETA, J.L. et al. 1998. Influence of weaning on carcass quality, fatty acid composition and meat quality in intensive lamb production systems. J. Anim. Sci., 66:175-87. 
954 Rev. bras. zootec.

SAS, Institute Inc. Users guide: Statistics. 1985. Version 5 Edition. Cary NC: SAS Institute Inc. 955p.

SILVA, L.F., PIRES, C.C., ZEPPENFELD, C. et al. Estudo da composição e características da carcaça de cordeiros. In: REUNIÃO ANUAL DA SOCIEDADE BRASILEIRA DE ZOOTECNIA, 35, 1998, Botucatu, SP. Anais... Botucatu: SBZ. 1998. p.515-17.

SILVA, L.F., PIRES, C.C., GUERRA, D.P. et al. Crescimento de osso, músculo, gordura e principais cortes da carcaça de cordeiros abatidos com diferentes pesos. In: REUNIÃO ANUAL DA SOCIEDADE BRASILEIRA DE ZOOTECNIA, 36, 1999, Porto Alegre, RS. Anais... Porto Alegre: SBZ, 1999a. p.353.

SILVA, L.F., PIRES, C.C., PEIXOTO, L.A. et al. Constituintes corporais de cordeiros abatidos com diferentes pesos. In: REUNIÃO ANUAL DA SOCIEDADE BRASILEIRA DE ZOOTECNIA, 36, 1999, Porto Alegre, RS. Anais... Porto Alegre: SBZ, 1999b. p.354.

SIQUEIRA, E.R., FERNANDES, S., MESQUITA, V.S. et al. Efeito do peso ao abate sobre a eficiência de produção de cordeiros da raça Hampshire Down terminados em confinamento. In: REUNIÃO ANUAL DA SOCIEDADE BRASILEIRA DE ZOOTECNIA, 35, 1998, Botucatu, SP. Anais... Botucatu: SBZ, 1998. p.704-06.
SOUSA, O.R.C. Rendimento de carcaça, composição regional e física da paleta e quarto em cordeiros Romney Marsh abatidos aos 90 e 180 dias de idade. Pelotas, RS: UFPel, 1993. 102p. Dissertação (Mestrado em Zootecnia) - Universidade Federal de Pelotas, 1993.

SUMMERS, R.L., KEMP, J.D., ELY, D.G. et al. 1978. Effects of weaning feeding systems and sex of lamb on lamb carcass characteristics and palatability. J. Anim. Sci., 47(3):623-29.

Recebido em: 17/08/00

Aceito em: 20/02/01 